\title{
Erratum to: Cytomegalovirus anterior uveitis: long-term follow-up of immunocompetent patients
}

\author{
M. Accorinti - M. Gilardi • M. P. Pirraglia • G. M. Amorelli • \\ C. Nardella • I. Abicca $\cdot$ F. R. Pesci
}

Published online: 9 November 2014

(C) Springer-Verlag Berlin Heidelberg 2014

\section{Erratum to: Graefes Arch Clin Exp Ophthalmol \\ DOI 10.1007/s00417-014-2782-4}

The original version of this article contained an error.

Particularly, it is stated that only in the abstract the two cohorts are made up of 9 and 9 patients, respectively. The actual number of the second cohort is 6 . The number of patients of the two cohorts reported throughout the manuscript is correct.

The online version of the original article can be found at http://dx.doi.org/ 10.1007/s00417-014-2782-4.

M. Accorinti $(\triangle) \cdot$ M. Gilardi $\cdot$ M. P. Pirraglia $\cdot$ G. M. Amorelli

C. Nardella $\cdot$ I. Abicca $\cdot$ F. R. Pesci

Servizio di Immunovirologia Oculare, Sapienza Università di Roma,

Viale del Policlinico 155, 00167 Rome, Italy

e-mail: massimo.accorinti@tiscali.it 